\title{
Developmental Anatomy of Lesions on 'Sunburst' Mandarin Leaves Initiated by Citrus Rust Mite Feeding
}

\author{
D.S. Achor, L.G. Albrigo, and C.W. McCoy \\ University of Florida, IFAS, Citrus Research and Education Center, 700 Experiment Station Road, \\ Lake Alfred, FL 33850
}

Additional index words. Phyllocoptruta oleivora, citrus, feeding injury, histology

Abstract. Upper surface leaf lesions on 'Sunburst' mandarin [( Citrus reticulata Blanco $\times$ ( C. paradisi Macf. $\times$ C. reticulate )] associated with feeding by the citrus rust mite [ Phyllocoptruta oleivora (Ashm.)] are more severe than those on other citrus cultivars. Development of leaf lesions on 'Sunburst' mandarin and two other cultivars were examined by light and electron microscopy. Damaged leaves treated with a fungicide confirmed that the anatomical changes on 'Sunburst' are an enhanced wound periderm response to feeding injury by rust mite and not the result of fungal invasion.

Typical citrus rust mite injury to leaves of citrus cultivars results in slightly rough brown to black spots or blotches confined to either the upper (adaxial) or lower (abaxial) leaf epidermis (Albrigo and McCoy, 1974; Grossembacher, 1923). When injury is severe, large, continuous areas of epidermis have a dull bronze-like color and a slightly rough texture (Hubbard, 1885; McCoy, 1976; Yothers and Mason, 1930). Mesophyll collapse, described in other citrus disorders (Haas, 1937; Turrell et al., 1948) and characterized by chlorosis, collapse of spongy mesophyll, and subsequent enlargement of cells adjacent to collapsed cells, has been reported in severe damage to the lower leaf surface (Albrigo and McCoy, 1974). Severe injury resulting in wound periderm formation has been observed in fruit and lower leaf epidermis but not in association with the upper leaf surface (Albrigo and McCoy, 1974; McCoy and Albrigo, 1975).

A dark "blister-like" lesion forms on the upper surface of leaves and young stems of a new commercial cultivar, Sunburst mandarin, in groves infested with citrus rust mite. Albrigo et al. (1987) concluded that the injuries on 'Sunburst' were a latent response to earlier mite feeding because trees sprayed regularly with insecticide for controlling citrus rust mite had little or no damage. However, the leaf lesions were more severe than typical mite damage on foliage of other cultivars.

In citrus, certain fungi can cause damage similar to that observed in 'Sunburst' mandarin. For example, melanose, caused by Diaporthi citri, is easily distinguished from rust mite injury in most citrus cultivars in that melanose lesions are more raised, much wider, and darker (Thompson, 1937). Lesions on 'Sunburst' have characteristics of both rust mite injury and melanose lesions. Raised lesions on the lower leaf surface characteristic of greasy spot, caused by Mycospharella citri Whiteside, result from hypertrophy of the spongy mesophyll cells (Whiteside, 1972). This response is similar to the enlargement of spongy mesophyll cells adjacent to areas of mesophyll collapse caused by rust mite injury to the lower leaf epidermis (Haas, 1937; Turrell, 1943). Van Brussel (1975) established in several field experiments that rust mite injury on leaves is correlated with increased severity of greasy spot infections.

Received for publication 15 June 1990. Florida Agricultural Experiment Station Journal Series no. R-00648. The cost of publishing this paper was defrayed in part by the payment of page charges. Under postal regulations, this paper therefore must be hereby marked advertisement solely to indicate this fact.
The apparent similarities of mite damage on 'Sunburst' to symptoms of these fungal diseases suggested that fungi might be involved in the development of the severe lesions attributed to mite damage on 'Sunburst'. The objectives of our study were to 1) determine histologically and cytologically the relationship between the unique lesions on 'Sunburst' and typical rust mite injury found on other citrus cultivars and 2) determine whether fungi associated with lesions on 'Sunburst' had any role in lesion development.

\section{Materials and Methods}

In June 1988, 120 leaves of spring flush with visible symptoms of damage to the upper leaf surface from citrus rust mite feeding were tagged on unsprayed 'Sunburst' trees. Half of these leaves were dipped monthly in Kocide 101 (a cupric hydroxide fungicide) (Griffin Corp., Valdosta, Ga.) at a rate of $2.03 \mathrm{~g} \cdot$ liter $^{-1}$ to prevent fungal development. Treated and nontreated samples, consisting of four to five leaves with stems, were collected monthly from June to January. At the same time, similar samples showing rust mite injury were collected from spring flush of unsprayed 'Marsh' grapefruit ( C. paradisi Macf.) and 'Valencia' orange (C. sinensis Osbeck) trees.

Scanning electron microscopy (SEM). Sample areas of leaf, petiole, and stem with visible leaf injury were fixed for 3 to 4 $\mathrm{h}$ at room temperature in 3\% glutaraldehyde in $0.1 \mathrm{M}$ potassium phosphate buffer at $\mathrm{pH}$ 7.2. Samples were washed in buffer, post-fixed 3 to $4 \mathrm{~h}$ at room temperature in $2 \% \mathrm{OsO}_{4}$ in the same buffer, and dehydrated in a graded series of ethanol. The samples were dried in a Ladd critical point dryer (Ladd, Burlington, VT) using bone dry $\mathrm{CO}_{2}$, mounted on stubs, and coated with 100 to $200 \AA$ gold using a Ladd sputter coater. Observations were made with a Hitachi S530 scanning electron microscope at $20 \mathrm{kV}$ and $100 \mathrm{~mA}$ current.

Light and transmission electron microscopy (TEM). Small areas of the damaged tissue were fixed as above, dehydrated in acetone, and embedded in Spurr's plastic (Spurr, 1969). For light microscopy, $1-\mu \mathrm{m}$ cross sections of leaf, stem, and petiole were cut using an LKB Huxley ultramicrotome (LKB, Cambridge Instruments, Deerfield, Ill.) and stained with $0.1 \%$ toluidine blue (O'Brien et al., 1964). Light micrographs were photographed with a Minolta SRT101 35-mm camera mounted on a standard Zeiss phase contrast microscope. For TEM, gold to silver sections of injured areas were mounted on copper grids, stained with methanolic uranyl acetate (Stempack and Ward, 
1964) for $15 \mathrm{~min}$, and post-stained with lead citrate (Reynolds, 1963 ) for $5 \mathrm{~min}$. Sections were viewed on a Philips 201 transmission electron microscope.

Histochemistry. Free-hand sections were made from unfixed leaves with initial damage collected in June; with raised lesions in October; and with advanced lesions in January. Leaf sections were treated with phloroglucinol-HCl (Johansen, 1940; Schneider, 1981) for detection of lignin and wound gum; the Maule test (Crocker, 1933) for lignin; and Sudan IV (Rawlins, 1933) for suberin, cutin, and other lipids.

\section{Results and Discussion}

Lesion development on 'Sunbunst', 'Valencia', and 'Marsh'. 'Sunburst' leaves collected in June had minimal injury, which was visible as a light browning on the petiole and along the midrib at the base of the leaf. SEM confirmed the browning areas as feeding sites for the mites by the multiple feeding punctures per epidermal cell (Fig. 1A). Microscopic comparison of leaf sections showing initial injury demonstrated that the epidermal cells in 'Sunburst' and in the other citrus cultivars studied developed four distinct responses to rust mite feeding: 1)
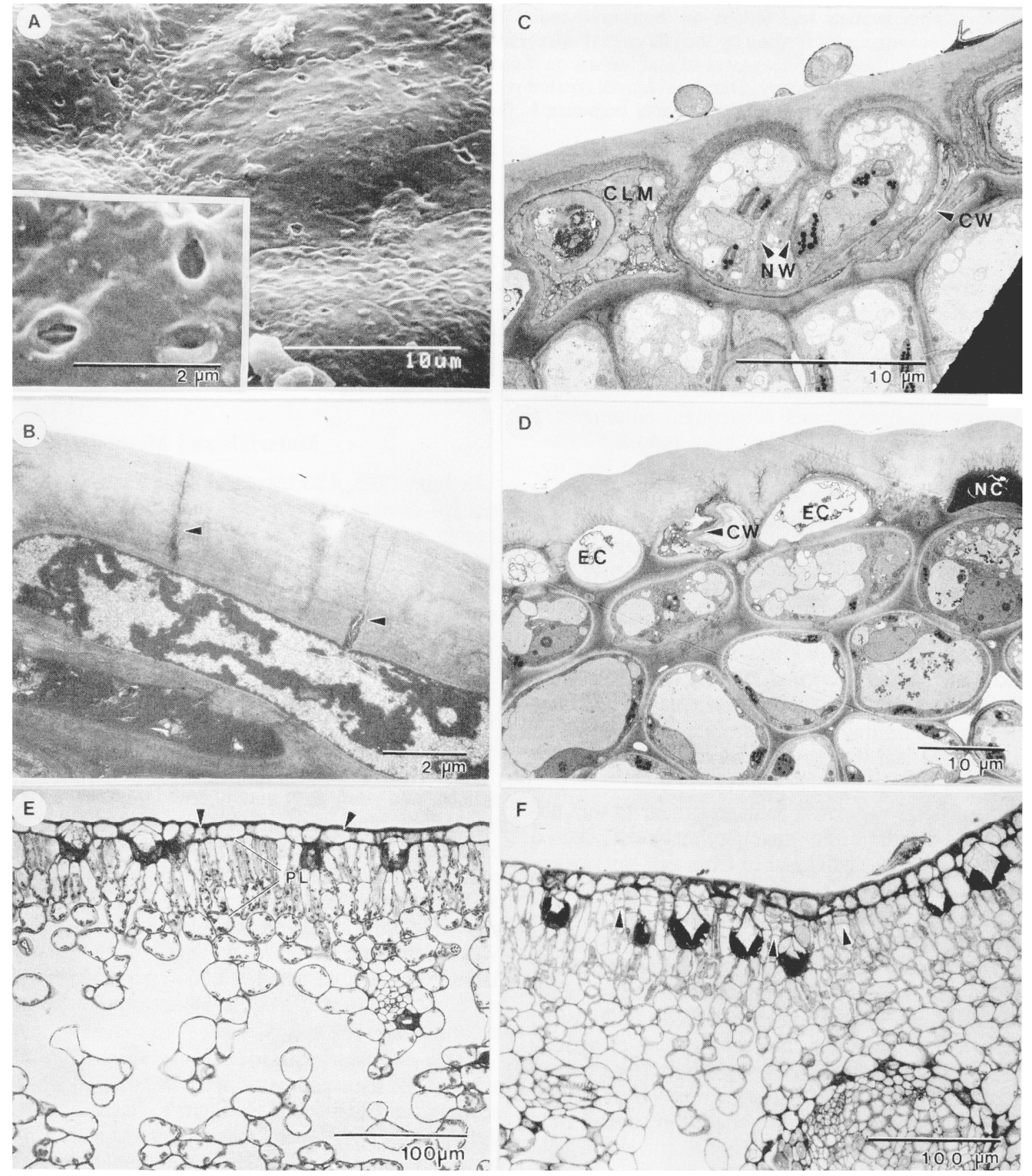

Fig. 1. Samples with (A-D, F) and without (E) minimal mite injury collected in June from 'Sunburst' mandarin. (A) SEM of mite punctures in upper leaf surface near the midvein. (B) TEM of similar injury showing partially evacuated cells with disintegrating organelles. Arrows = puncture sites. (C) TEM of upper, leaf epidermis demonstrating collapsing cell (CW), dividing cell synthesizing new wall (NW), and disintegrating organelles with cytoplasm being filled with cutin-like material (CLM). (D) TEM of petiole epidermis with evacuated cell (EC) and necrotic cell (NC). (E) Light micrograph of undamaged area of leaf with smooth, transparent epidermal layer (arrows) and typical palisade layer (PL). (F) Light micrograph showing periclinal divisions (arrows) in palisade beneath damaged epidermal cells. 
evacuation, caused by direct feeding, of cellular organelles with only membrane fragments and a fine precipitate remaining (Fig. $1 \mathrm{~B}, \mathrm{D})$; 2) cellular collapse after evacuation and replacement by cell divisions in adjoining healthy cells (Fig. 1C); 3) injured or evacuated cells filled with a cutin-like material (Fig. 2A) that stained light green with toluidine blue in $1-\mu \mathrm{m}$ sections as does the cuticle in damaged areas; and 4) cellular necrosis (Fig. 1D). Necrotic epidermal cells stained blue-black in light microscopy and were electron dense in TEM. In response to histochemical tests, the contents and walls of these cells stained intensely with phloroglucinol, the Maule test, and Sudan IV, indicating the presence of lignin, wound, gum, and suberin (Schneider, 1980), as is typical of a wound closing layer or boundary zone (Biggs and Stobbs, 1985; Esau, 1965).

Injury was easily detected in these leaves when compared with an uninjured area consisting of a transparent epidermal layer and two cell layers in the palisade zone (Fig. IE). Cell division in the palisade cells in response to epidermal injury marked the initiation of wound periderm formation (Fig. 1F) in these June samples. The type of injury observed on 'Valencia' and 'Marsh' grapefruit leaves was the same as that on 'Sunburst', but more leaves were affected on 'Sunburst'.

By July and August in 'Sunburst', injured areas were more extensive, dark brown, and slightly raised in appearance. Cytologically, most of the epidermal cells were either necrotic (Fig. 2A) or evacuated. The initiation of cell wall thickening and suberization in a few cells below the injured epidermis marked the initiation of a phellem layer. The phelloderm had developed up to four to five layers (Fig. 2B). Enlargement of these cells began giving the lesions their raised appearance.

A typical fully developed wound periderm usually consists of three tissues: the phellem, phellogen, and phelloderm (Esau, 1965). Lesions on 'Valencia' and 'Marsh' (Fig. 2C) consisted of two to three cell layers of phelloderm below the phellogen, creating flatter lesions than those on 'Sunburst'. At this time, these lesions had not developed a phellem layer, leaving the intact, necrotic epidermis to act as the closing layer (Briggs and Stobbs, 1985). Fig. 2C also shows evidence of necrosis and cell divisions associated with mite feeding on the lower leaf surface in these cultivars that was not observed in 'Sunburst' (Fig. 2B). The anatomical structure of the lesions was typical for 'Valencia' and 'Marsh' from July to December with no further changes occurring until January (end of the experiment) in these cultivars. In addition, there were fewer affected leaves per tree and the lesions were smaller in 'Valencia' and 'Marsh' than in 'Sunburst' throughout the season.

Lesions were very dark and blister-like on 'Sunburst' leaves collected in September. In the injured tissue, the phelloderm consisted of five to six layers of elongated cells (Fig. 3A). A continuous layer of collapsed cells, with thickened, suberized cell walls (phellem) appeared between the phellogen and the necrotic epidermal cells (Fig. 3 A, B). The thickened cell walls stained weakly positive with the Maule test and strongly positive with Sudan IV, indicating the presence of lignin and a strong suberin component, as has been shown in wound periderm formation in the lower leaf and fruit surfaces in other citrus cultivars (Albrigo and McCoy, 1974; McCoy and Albrigo, 1975). Ultrastucturally, these cells possessed the typical lamellae in the walls characteristic of suberin (Biggs and Stobbs, 1985; Dean and Kolattukudy, 1976; Espelie et al., 1980) (Fig. 3C). The necrotic epidermal cells had become darker and evacuated epidermal cells had collapsed. There was evidence that the cuticle was beginning to lose integrity and a layer of resident fungi
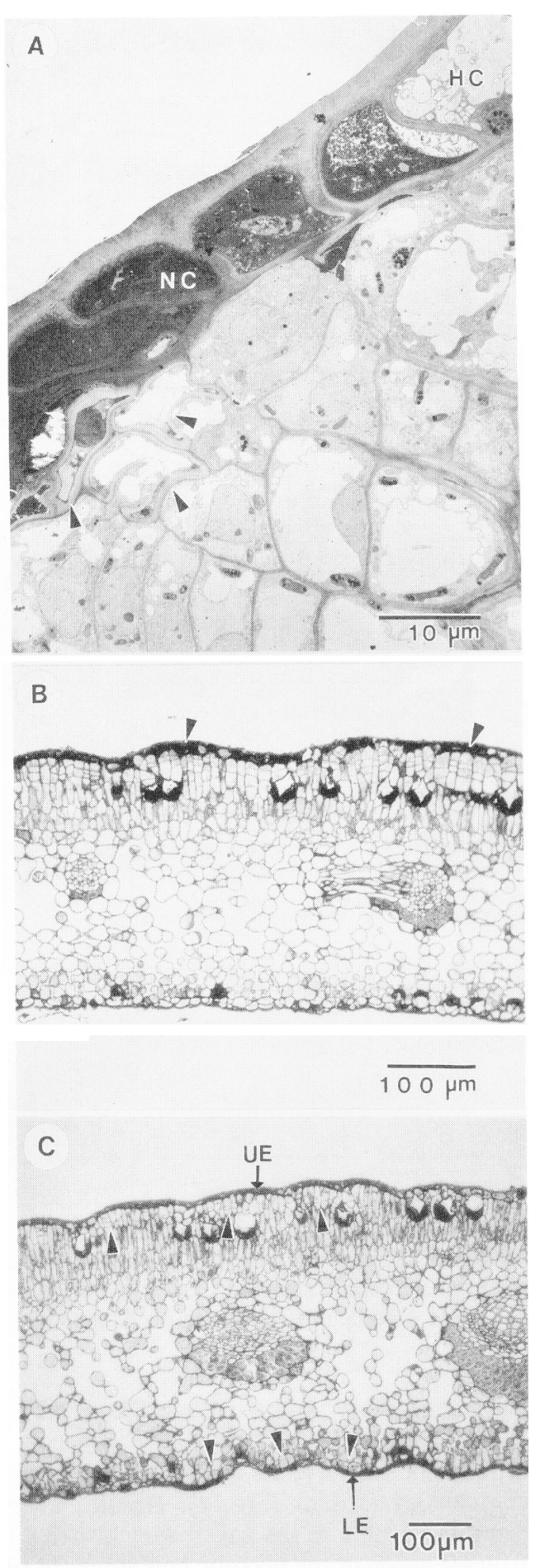

Fig. 2. 'Sunburst' and 'Marsh' leaves collected in July and August. (A) TEM of necrotic (NC) and healthy cells (HC) in the leaf epidermis of 'Sunburst'. Multiple cell divisions are apparent in the palisade layer. Arrows point out initial development of suberization, leading to differentiation of a layer of phellem. (B) Light micrograph of extensive necrosis in the upper epidermis (arrows) in 'Sunburst'. Note the roughness of the upper epidermis created by cell divisions in the palisade layer. (C) Light micrograph of typical injury found on 'Marsh' from September through December. Upper epidermis (UE) is totally necrotic. Cell divisions (arrows) occurring without phellem formation in the palisade layer. Note the necrosis of the lower epidermis (LE) with cell divisions (arrows) in the cell layer above it. 


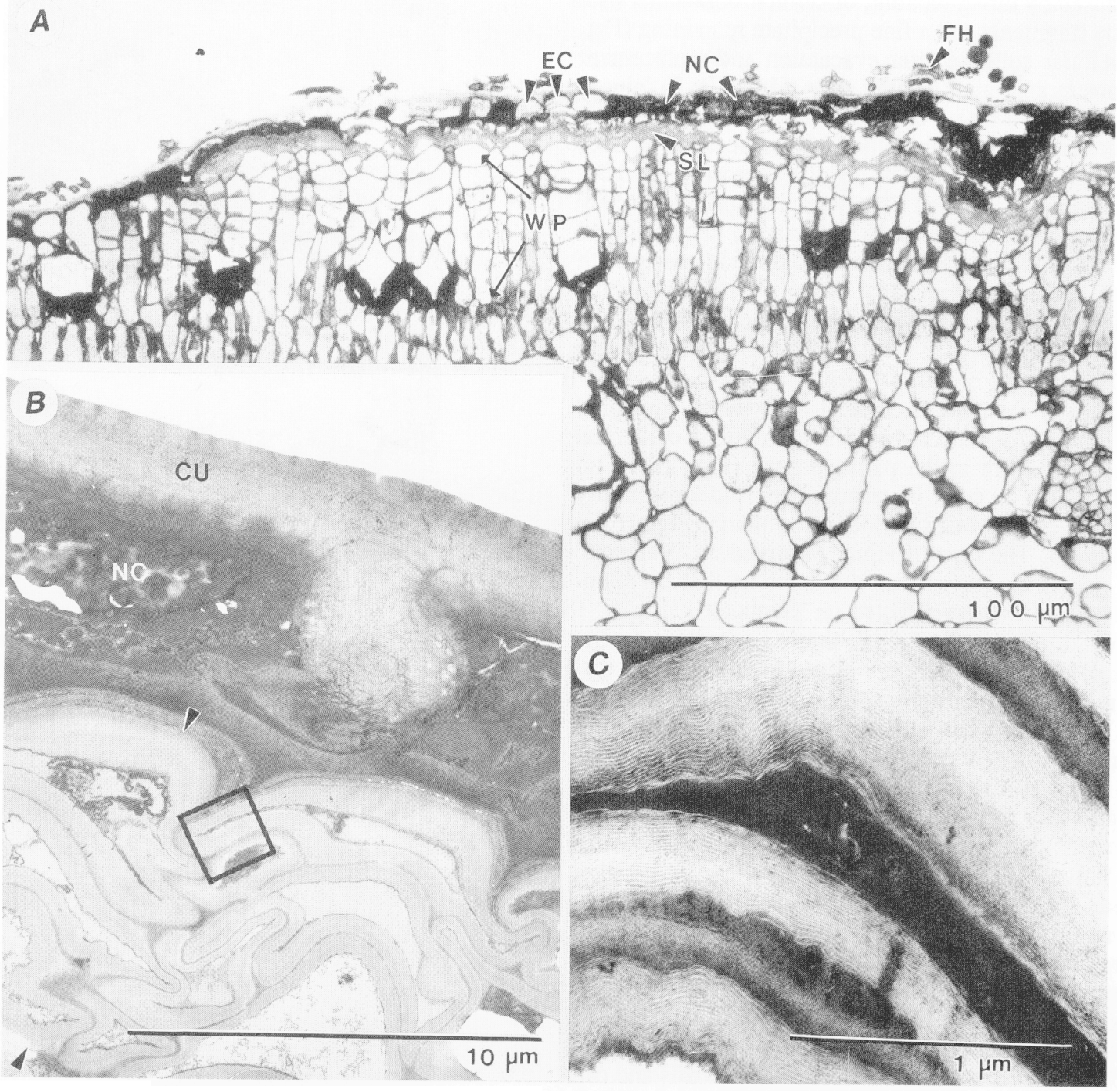

Fig. 3. Lesions on spring flush of 'Sunburst' collected in September. (A) Light micrograph of lesion showing the extent of its development. $\mathrm{EC}=$ evacuated cells in epidermis, $\mathrm{NC}=$ necrotic cells, $\mathrm{FH}=$ fungal hyphae, arrow = weakened area of cuticle, WP = wound periderm (phellogen + phelloderm) extending six cell layers, SL = suberized layer (phellem). (B) Necrotic epidermis (NC) and phellem (area between two arrows). $\mathrm{CU}=$ cuticle. $(\mathbf{C})$ Area in phellem similar to boxed area in (B). Note suberin lamellae in these thickened walls.

covered the outer surface of the untreated leaves by this time (Fig. 3A).

By December and January, the phelloderm in 'Sunburst' was six to seven cell layers thick (Fig. 4). Fissures in the lesions were frequent and visible to the naked eye. Invasive fungi had begun to degrade much of the necrotic epidermis. In some areas only degraded cell walls remained between the cuticle and the phellem (Fig. 4B). However, the fungal hyphae were never observed to penetrate through the phellem into the healthy tissue below, as has been reported in many studies concerning wound periderm and pathogen invasion (Biggs et al., 1984; Bostock and Stermer, 1989).

In January, severe lesions with fissures were found on only a few leaves and stems in 'Valencia' and 'Marsh'. The typical response in these cultivars throughout this study was as that found in 'Sunburst' and 'Marsh' in June (Fig. 2 B, C), consisting of extensive epidermal necrosis with one to three layers of phelloderm cells but no phellem layer.

Role fungi in lesion development. The relationship of mode and time of fungal entry was analyzed by scanning electron microscopy (SEM) of the leaf surface to determine whether fungi played a role in increasing the severity of the wound response. Fungi did not appear to be penetrating areas with intact cuticle, but entered areas with fissures in the cuticle. Because fissures of 100 to $200 \mu \mathrm{m}$ developed on treated leaves in the absence of fungi (Fig. 5A), we concluded that pressure from wound periderm formation on the weakened epidermis was responsible for fissure formation and not digestion by fungal enzymes.

Lesions on Kocide-treated leaves collected in January were as large and possessed the same anatomy (Fig. 5B) as those on untreated samples. Consequently, we conclude that fungi were secondary invaders into necrotic tissue and had little to no effect on lesion size or severity. Invading fungi were not identified, but appear to represent several species.

Citrus mite injury has a very different appearance on leaves of 'Sunburst' mandarin than on other citrus cultivars, such as 'Valencia' and 'Marsh'. Fungi were suspected to be partially 


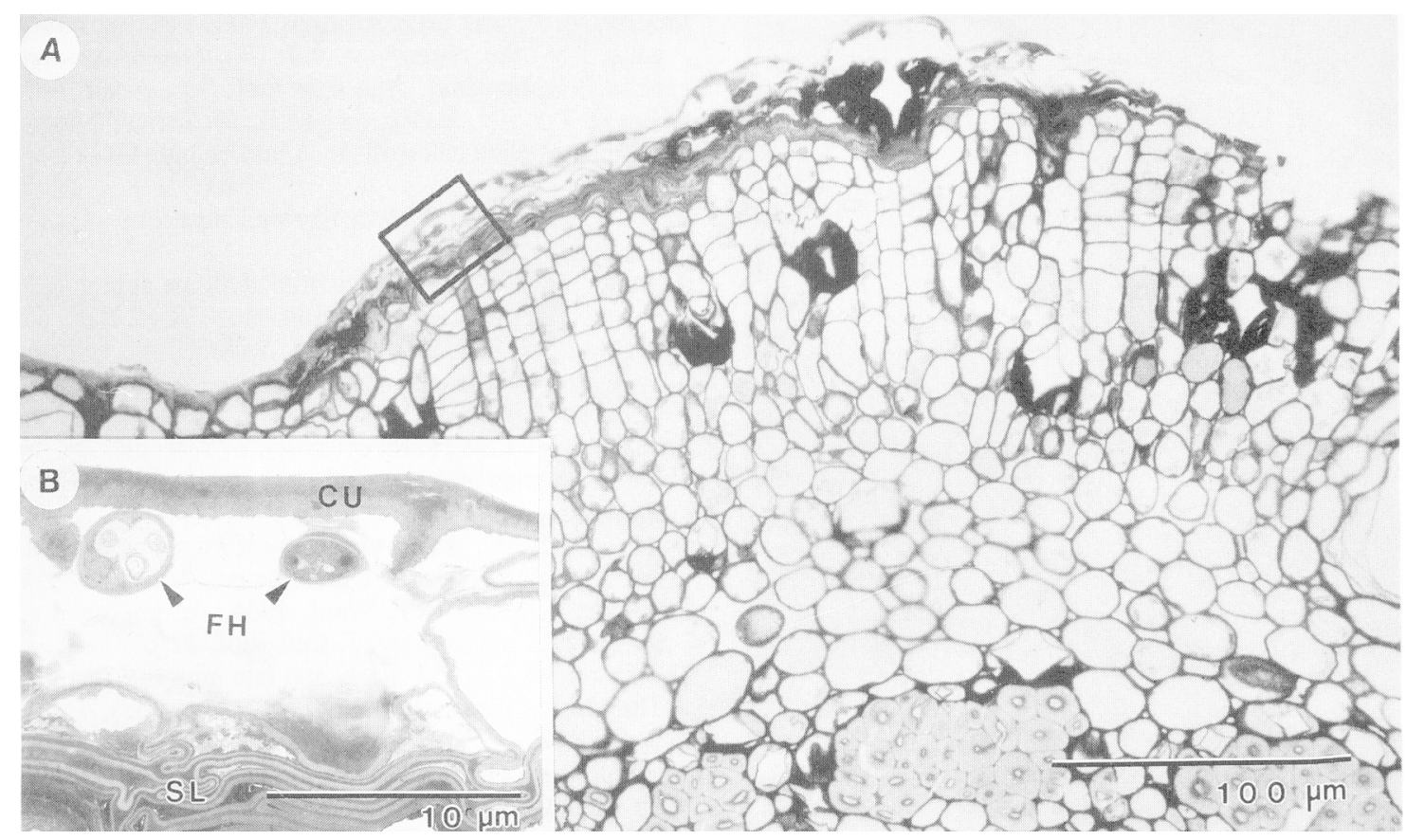

Fig. 4. Lesions on spring flush of 'Sunburst' collected in December and January. (A) Light micrograph of area over midvein showing the of lesion development. (B) TEM (similar to boxed area) shows complete degradation of necrotic cells by fungal hyphae (FH) that $\mathrm{d}$ from fissure not shown in section. $\mathrm{CU}=$ cuticle, $\mathrm{SL}=$ suberized layer (phellem).

responsible for the damage on 'Sunburst' because of the more exaggerated response. Our results demonstrated that lesion development was as common and severe on leaves treated monthly with fungicide as on untreated leaves. Consequently, we conclude that the lesions unique to 'Sunburst' are a result of extensive periderm formation and are not associated with invasive fungi.

Like fungal populations, citrus mite populations do not appear to be related to the severity of lesion development. Leaves of spring flush of 'Sunburst' used in this study had a higher density of rust mites than 'Valencia' and 'Marsh'. However, in 1988, 'Sunburst' had lower mite populations but more leaf injury than the other cultivars. Site feeding preference of citrus mites may explain the more frequent formation of wound periderm on the upper leaf surface in 'Sunburst' and on the lower surface in 'Valencia' and 'Marsh'. Conflicting results have been reported for population counts on leaf surfaces for grapefruit and 'Valencia' (Thompson, 1937; van Brussel, 1975; Yothers and Mason, 1930) and require clarification. Future studies should clearly establish whether mite feeding preference is related to leaf surface or cultivar.

The anatomical changes in 'Sunburst' mandarin leaves in response to injury by citrus mite feeding were very different than on leaves of the other citrus cultivars studied. Wound periderm formed on the upper surface of 'Sunburst' leaves and on the upper and lower surfaces of other cultivars. The wound periderm formed on 'Sunburst' leaves consisted of phellem, phelloderm, and phellogen, but leaves of the other cultivars did not generally develop a phellem layer, except in a few severe cases. Phelloderm consisted of up to seven layers of cells in 'Sunburst' leaves and of only two or three cell layers in other cultivars. The reason for a more extensive wound periderm in the upper leaf surface of 'Sunburst' compared with its less severe occurrence in the upper and lower leaf surfaces of 'Valencia' and 'Marsh' is unknown. Studies that measure differences in cellular response to injury may answer this question.

\section{Literature Cited}

Albrigo, L.G. and C.W. McCoy. 1974. Characteristic injury by citrus rust mite to orange leaves and fruit. Proc. Fla. State Hort. Soc. 87:48-55.

Albrigo, L. G., C.W. McCoy, and D.P.H. Tucker. 1987. Observations of cultural problems with the 'Sunburst' mandarin. Proc. Fla. State Hort. Soc. 100:115-118.

Biggs, A.R. and L.W. Stobbs. 1985. Fine structure of the suberized cell walls in the boundary zone and necrophylactic periderm in wounded peach bark. Can. J. Bet. 64:1606-1610.

Biggs, A. R., W. Merrill, and D.D. Davis. 1984. Discussion: Response of bark tissues to injury and infection. Can. J. For. Res. 14:351356.

Bostock, R.M. and B.A. Stermer. 1989. Perspectives on wound healing in resistance to pathogens. Annu. Rev. Phytopathol. 27:343371.

Crocker, E.C. 1933. Maule lignin test on Podacarpus wood. Bet. Gaz. 95:168-171.

Dean, B.B. and P.E. Kolattukudy. 1976. Synthesis of suberin during wound healing in jade leaves, tomato fruit and bean pods. Plant Physiol. 58:411-416.

Esau, K. 1965. Plant anatomy. 2nd ed. Wiley, New York.

Espelie, K. E., R.W. Davis, and P.E. Kolattukudy. 1980. Composition, ultrastructure and function of the cutin- and suberin-containing layers in the leaf, fruit peel, juice-sac and inner seed coat of grapefruit (Citrus paradisi Macfed.). Planta 149:498-511.

Grossembacher, J.G. 1923. Controlling the rust mite to prevent rust. Citrus Leaf 31:3-6.

Haas, A.R.C. 1937. Mesophyll collapse of citrus leaves. Calif. Citrograph 22:114.

Hubbard, H.G. 1885. Rust of the orange. U.S. Dept. Agr. Rpt. of the Entomologist. p. 361-373.

Johansen, D.A. 1940. Plant microtechnique. McGraw-Hill, New York. McCoy, C.W. 1976. Leaf injury and defoliation caused by the citrus rust mite, Phyllocoptruta oleivora. Fla. Entomol. 59:403-410. 

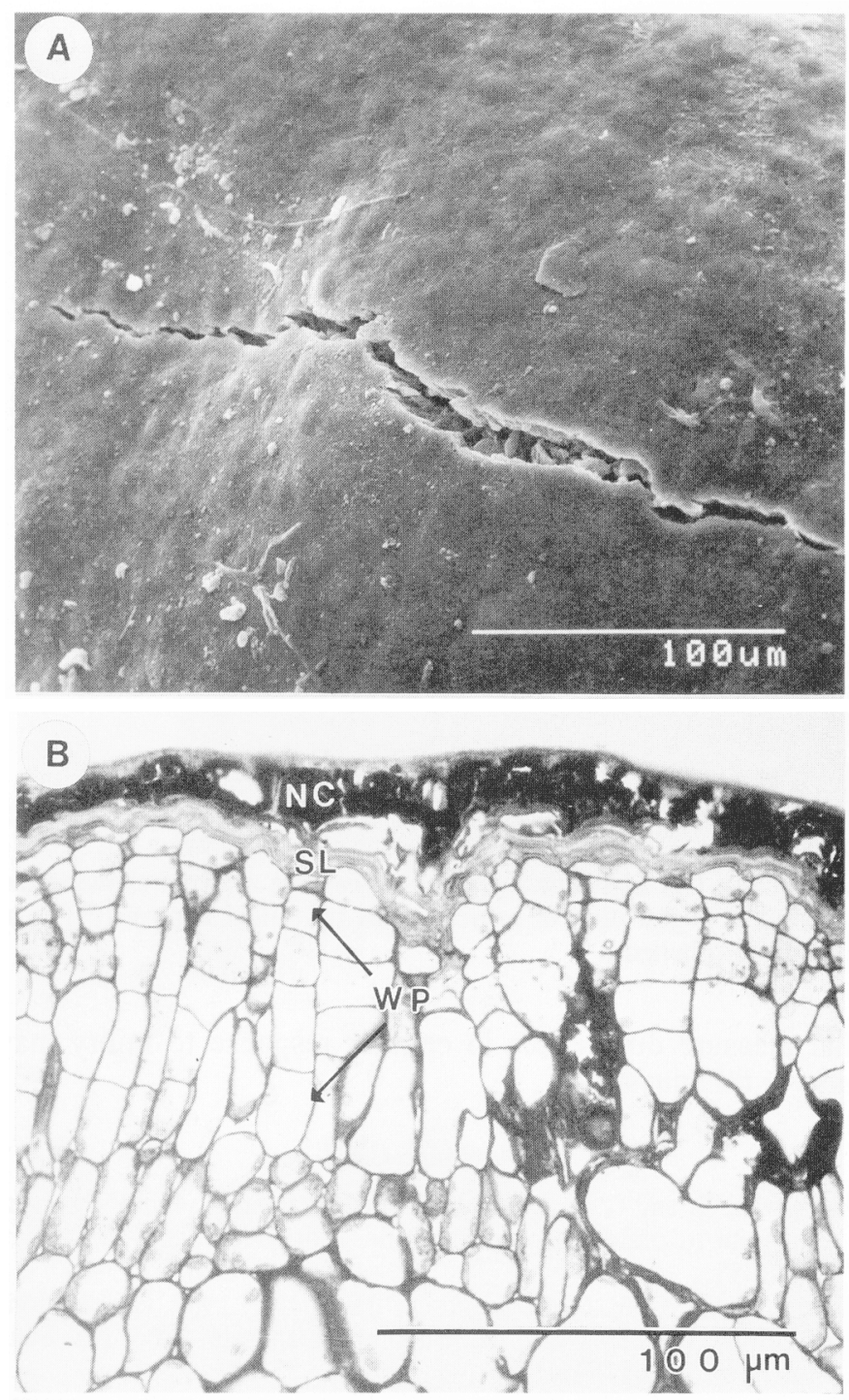

Fig. 5. Development of lesions in Kocide-treated 'Sunburst' leaves. (A) SEM of small fissure $(100$ to $200 \mu \mathrm{m})$ in lesion of Kocidetreated leaf collected in July. Note absence of fungi. (B) Light micrograph of cross section of January lesion in Kocide-treated 'Sunburst' leaf. $\mathrm{NC}=$ necrotic cells, $\mathrm{SL}=$ suberized layer (phellem), $\mathrm{WP}=$ wound periderm.
McCoy, C.W. and L.G. Albrigo. 1975. Feeding injury to the orange caused by the citrus rust mite Phyllocoptruta oleivora (Prostigmata:Eriophyoidea). Arm. Entomol. Soc. Amer. 68:289-297.

O'Brien, T.P., N. Feder, and M.E. McCulley. 1964. Polychromatic staining of plant cell walls by toluidine blue O. Protoplasm 59:367373.

Rawlns, T.E. 1933. Phytopathological and botanical research methods. Wiley, New York.

Reynolds, E.S. 1963. The use of lead citrate at high $\mathrm{pH}$ as an electronopaque stain in electron microscopy. J. Cell Biol. 17:208-212.

Schneider, H. 1980. Deposition of wound gum, callose and suberin as responses to diseases and wounding of citrus. Bul Soc. Bot. Fr. 127:143-150.

Schneider, H. 1981. Plant cytology, p. 339. In: G. Clark (ed.). Staining procedures for biological stain commission. Williams \& Wilkins, Baltimore.

Spurr, A.R. 1969. A low-viscosity epoxy resin embedding medium for electron microscopy. J. Ultrastructure Res. 26:31-43.

Stempack, J.C. and R.T. Ward. 1964. An improved staining method for electron microscopy. J. Cell Biol. 22:697-701.

Thompson, W.L. 1937. Early and late injury of rust mites on oranges. The Florida Insecticide Co. (FICO) News 5:3,7-9.

Turrell, F. M., V.P. Sokoloff, and L.J. Klotz. 1948. Structure and composition of citrus leaves affected with mesophyll collapse. Plant Physiol. 18:463-475.

van Brussel, E. W. 1975. Interrelations between citrus rust mite, Hirsutella thompsonii and greasy spot on citrus in Surinam. Agr. Expt. Sta. Surinam Bul. 98:1-66.

Whiteside, J.O. 1972. Histpathology of citrus greasy spot and identification of the causal fungus. Phytopathology 62:260-263.

Yothers, W.W. and A.C. Mason. 1930. The citrus rust mite and its control. U.S. Dept. Agr. Tech. Bul. 176:1-16. 